\title{
Drones in Construction: A comparative international review of the legal and regulatory landscape
}

\section{Andrew Agapiou \\ Department of Architecture, University of Strathclyde, Glasgow}

\begin{abstract}
Increasingly, construction companies are using drone technology for a variety of purposes including conducting aerial surveys and monitoring the activities of staff and subcontractors on the construction worksite. As the technology develops newly adopted drone laws and the application of current laws to drone use are areas of concern as governments grapple to regulate the operators, manufacturers and systems. While the commercial benefits of using drones on the construction site are not fully understood or realized, companies need to keep abreast of changes to the legislation and regulations that govern drone usage. This paper reviews the regulatory and legal schemes for drone operation within the construction industry in the USA, UK, Japan, Australia and Hong Kong. Drone technology, infrastructure, regulations and standards are continually evolving, with collaborative research and development across all these areas. Whilst this offers exciting opportunities to private and public sectors worldwide, such rapid change and growth is a challenge for regulators, to ensure that regulation and infrastructure is in place in time to manage and meet these changes. The proposed research agenda offers a guide for future research on the legal aspects of drone operation for the construction sphere.
\end{abstract}

\section{Introduction}

Drones are unmanned, remotely controlled small aircraft. Although originally used for military purposes, the commercial use of drones has increased (Mosly, 2017). The Teal Group's 2015 market study estimates the global aerial drone market over the coming decade to grow from $£ 3.22$ bn to $£ 11.27$ bn in 2025 , totalling $£ 74.85$ bn (Finnegan, 2018) in the next ten years. A May 2016 Price Waterhouse Coopers report estimated the emerging global market for business services using drones at over $£ 102$ bn (Price Waterhouse Coopers, 2018) 
In the construction industry drones represent a useful tool for surveying; identifying hazard and building maintenance issues; thermal imaging; volumetric analysis; inspecting structures and monitoring the environmental impact of projects.

The regulation on the use of drones involves international and national regulations. The rapid development of drones has been possible because unlike manned aircraft there is no regulation regarding its design and production; this allows testing of new technologies (Kasprzyk and Konert, 2018). Drones must meet the standards of manned aircraft regarding airworthiness and the rules of the air. In practice, however, this is not possible, and problematically, civil aviation regulations at both national and international levels have been developed on the assumption that there are professional people in the aircraft who supervise flight operation. Furthermore, safety requirements are geared towards protecting passengers. This makes such regulations non-applicable to unmanned aircraft (Kasprzyk and Konert, 2018) which represent 'disruptive technology' (Du and Heldeweg, 2019), carrying specific requirements, inter alia: airworthiness; radio frequencies for data transmission; motion detection and systems to avoid collision; emergency systems, for instance in case communication is lost; training and competence of drone operators, and, application of air rules including procedures for air traffic services (Kasprzyk and Konert, 2018). Relevant national authorities have also introduced operations permission system, to ensure commercial companies wanting to use drones or anyone wanting to test new ways of using drones do so responsibly and safely. Relevant non-aviation specific rules, including data protection, trespass and terrorism laws, also need to be complied with globally.

There is a plethora of research on the technical capabilities of drone technology (e.g. robotics, control and computer vision), but much less research on the legal and regulatory aspect of drone operation and usage within the construction sphere. This paper will review the regulatory and legal schemes for drone operation within the USA, UK, Japan, Australia and Hong Kong.

Similarities and contrasting elements in the various national drone regulations and their implications for data acquisition activities within the constructed environment will be explored. Finally, conclusions are drawn and directions for future work suggested. 


\section{Drone Regulation Research}

The legal and regulatory aspect of drone technology, operation and usage have already been mentioned in various publications - a refined Google Scholar search found more than 17000 publications (conference paper, articles, reviews ...) from the year 2012 onwards.

Nevertheless, the authors of relevant articles either discuss the topic from the perspective of one context (e.g., privacy), technical specification (e.g., sense and avoid systems) or cover only a few countries. Although the legal provisions are one important part of the preparation phase of drone data acquisition flights, most technically or application-oriented articles do not specifically mention the regulations that were applicable to their data collection flights [Watts et al, 2012]. Some review articles on drone applications discuss legislative frameworks: they present national and international regulatory bodies and give short introductions to risk-based approaches, drone safety level classifications and current efforts of international organisations to harmonize drone legislation [Nex and Remondino, 2014; Colomina, and Molina, 2014; Honkavaara et al, 2014]. However, the works provide only brief overviews and remain highly generalized. Currently, there is also a dearth of knowledge on the legal and regulatory framework required to promote the wider adoption of drone technology within the constructed environment (Stocker et al, 2017).

\section{Regulatory environments}

Before analysing national regulatory environments, it should be mentioned that international parameters have been formulated. In 2011 the International Civil Aviation Organisation, a UN specialised agency which manages the Convention on Civil Aviation (Chicago Convention) 1944, published a circular on the use of unmanned aircraft (ICAO, 2011). It stipulated that only remotely piloted aircraft would be able to integrate into the international civil aviation in future because the responsibilities of the remote pilot form an integral part of the safety of the unmanned aircraft. As such, the pilot remains responsible for the drone (Du and Heldeweg, 2018). Furthermore, the Chicago Convention, despite being formed in 1944 refers to unmanned aircraft under Article 8, which states that they can only fly over a contracting State with special authorisation, and the State must ensure that the aircraft is controlled in order to obviate danger to civil aircraft (Chicago Convention, 1944) . 
It is submitted that this approach is problematic because it conceives drones as being akin to passenger aircraft rather than covering the specific tasks required in the construction industry. The section below highlights the legal and regulatory aspects of drone operation with a particular focus on when, where, under which conditions and by whom data can be captured.

\section{$\underline{U S A}$}

In the US, the Federal Aviation Administration issued the Unmanned Aircraft Rule (UAR) in 2016. It stipulates that the weight of an unmanned aircraft must be less than 25 kilograms (55 pounds) and the aircraft must remain within the visual line of sight of the operator or of a visual observer. Furthermore, the drone must remain within sight and 'close enough' to the remote pilot manipulating the flight controls of the aircraft in the event that something unexpected happens (FAA News, 2016). Additionally, the person operating the aircraft must have a remote pilot certificate or be supervised by a person who holds one. In order to obtain the remote pilot certificate, the person must demonstrate aeronautical knowledge by either passing an aeronautical knowledge test or hold an existing part 61 pilot certificate and complete a flight review; the person must be vetted by the Transportation Security Administration (FAA News (2016).

Furthermore, there is control over the flight height. The maximum altitude is 400 feet above sea level, at a maximum speed of 87 knots; drones can only fly during daytime or civil twilight, that is, 30 minutes before official sunrise and 30 minutes after official sunset (FAA News, 2016). As such, there is control not just over the drone itself but how the drone is operated. Apart from federal regulations, any drone operator must follow local regulations such as city ordinances banning flights over a city or within certain distance of landmarks and specified landing areas.

However, the FAA is keen to avoid a 'patchwork quilt' of different regulations from State to State and the aim is to subject all States to federal regulation only (Federal Aviation Administration, n.d).

Nevertheless, the patchwork quilt of State and local drone regulations continues apace, with two more States proposing drone laws that would severely limit commercial use. The introduction of new regulations in Montana and Oklahoma, for example, have been designed to protect personal property rights, go much further - limiting not only the drone industry but the potential benefit that drones could provide to those citizens. 
The regulations have prompted comment from industry leaders who fear that States will undo the regulatory progress made by the FAA.

In the US construction industry drones are used as an extra pair of eyes for large commercial projects or tall buildings as they provide an aerial view of progress of works at a particular time, thus allowing supervisors a good chance to detect any flaws, safety hazards or to check on workers (Liberty Mutual Insurance, 2016). However, as stipulated in the UAR, the drone must be visible to the pilot/operator at all times. It is therefore necessary to establish a clear path for the drone before flight and to be prepared to impose an emergency landing if necessary. According to international rules, the drone operator is liable, and if the contractor owns the drone, he will also be subject to potential liability (Liberty Mutual Insurance, 2016)

\section{Hong Kong}

Recreational drones are very popular in Hong Kong and this is aided by their low purchasing cost (Cheung, 2018). The growth in popularity prompted the Hong Kong's Civil Aviation Department to carry out consultation after several incidents due to a drone almost colliding with a rescue helicopter and injuries to people trying to avoid falling drones; due to lack of skill by amateur drone operators, crash landings are common (Cheung, 2018).

However, the current regulations seem to be insufficient by covering only drones used for commercial purposes or drones for whichever purpose that weigh more than 15.4 pounds (7 kilograms) (UAV Coach, n.d.). This leaves out all drones for recreational purposes, which can cause serious accidents; nevertheless, the HK Civil Aviation Department (HKCAD) has classified them as 'model aircraft flying' and free to fly without application to do so (Hong Kong Civil Aviation Department, n.d.). Yet, complaints about drones doubled in 2017 from 2015 in Hong Kong, involving drones flying in banned areas, including populated and congested districts and involving privacy issues (Leung, 2018).

For drones involved in commercial flights, the pilot must maintain records of each flight, and request permission for the flight. The operator is required to maintain and submit an operations manual covering the procedures formulated by the HKCAD. Unless this document is kept, permission to fly the drone is not granted. Additionally, drones cannot fly within 3.1 miles of an airport or be flown within 164 feet of a person, 
vessel, vehicle or structure except during take-off and landing. The operator must have visual contact with the drone at all times, fly it only during the day and not higher than 295 feet (UAV Coach, n.d.).

The construction industry in Hong Kong contributes to seven percent of the territory's GDP, but it has problems connected with manpower demand and an ageing workforce with skills mismatch. The industry has failed to attract the new generation into a business that is considered to be dirty, dangerous, demanding, and disorganised (Wong et al, n.d.). Accidents are common, showing one of the highest fatality rates among all industries within Hong Kong, with 3,232 industrial accidents reported in 2013, of which 22 were fatal (Wong et al, n.d.).

As such, drones are important for site monitoring with aerial overview at different stages in the project (Wong et al, n.d.). Advancements in drone technology could help reduce construction-related injury and death from falls, toxic chemical exposures, electrical hazards, or traumatic injury from vehicle and equipment collisions (Irizarry and Costa, 2016).

It is submitted that Hong Kong's regulations reflect the character of the territory, which is densely populated and with a concentration of high-rise structures. This poses challenges for protecting privacy and coordinating urban air traffic, which would not be applicable in rural areas.

\section{$\underline{\text { Japan }}$}

Japan has issued legislation restricting the use of drones, prompted by an incident in which a small drone was found on the roof of the Prime Minister's Tokyo office. Although at that time there was no legislation covering the use of drones, the operator was indicted and received a suspended sentence of two years' imprisonment under criminal law (Library of Congress, n.d.). The government amended the Aviation Act in 2015, which stipulates that in unrestricted areas, unmanned aircraft are required to stay below 492 feet (150 metres) and to be kept at least 98 feet (30 metres) away from people, buildings or vehicles. The legislation also imposed operational limitations such as flying drones only during daytime, keeping the drone within visual line of sight, and it made it unlawful to fly a drone over event sites where there are crowds (Library of Congress, n.d.) It is forbidden to fly drones in Tokyo's crowded residential areas or near 
airports without a permit from the Minister of Land, Infrastructure and Transportation (Nikkei Asian Review, 2015).

It is also forbidden to fly drones over any of Tokyo's 81 public parks and gardens (Drone Law Japan, n.d). The Japanese regulations relating to drone technology have been developed, keeping in view the function of drones in the commercial context. Nevertheless, terrorism and other security-related concerns have led to calls for stronger regulations for drones for hobby and recreational activities.

The construction industry in Japan is increasing mainly due to preparing the country for the Tokyo Olympics and to rebuild and prepare for natural disasters after the typhoons and heavy rains in 2018. This has resulted in a short supply of materials and manpower (Kawahara and Niunoya, 2019). Thus, drones are important in the construction industry to provide secure the delivery of projects; additionally, Japan has strict health and safety legislation under the Industrial Health and Safety Act, which stipulates that companies have to compensate employees for accidents at work; a breach carries a penalty of six months' imprisonment or JPY 500,000 (Suratkon, 2013). A Japanese company, Komatsu, is at the forefront of developing new drone technology for construction projects, including drones that generate accurate map data and eliminate the need for ground control points. Additionally, drones can survey the entire site in a short time regardless of machinery and people being present on the site, which facilitates daily surveys.

The drone data integrates with Komatsu's Smart Construction robotic earthmoving equipment to enable the equipment to precisely dig, bulldoze, and grade the terrain autonomously according to digital construction plans at the earthwork stage of the construction process (Construction Week Online, 2018).

\section{Australia.}

In Australia drone technology has been utilised in areas such as: disaster management; road surveying; three-dimensional mapping; infrastructure maintenance and management; pest and plant management; compliance management; and law enforcement. 
Australia has had unmanned aircraft regulations since 2002 (Library of Congress, n.d.). Regulation on drones is similar to that of the countries discussed above, in respect of daytime flying, height and visual contact with the drone. Additionally, operators of nonrecreational drones must hold a remote pilot licence and a licence certificate for aircraft weighing 25-150 kilograms/55-330.7 pounds (Library of Congress, n.d.). Australian regulations are more strict regarding flights over people, which are forbidden at all times, regardless of how high the drone is flying (Australian Government Civil Aviation Safety Authority, n.d.). There are still grey areas that require more clarity in the regulation. For instance, a drone operation that does not seek any "commercial gain" can operate without any certification but the concept of "commercial gain" can be interpreted in multiple ways. If an operator is using drones to advertise a product or if an operator seeks to shoot videos and upload onto YouTube, these may not see a direct commercial benefit, but they go to publicise a certain industry or an activity (O'Reilly, 2017).

As a large country, drones are very important in the construction industry in remote locations, where often the main hurdle is surveying the land (Locker, 2017). Early in 2017, the Civil Aviation Safety Authority (CASA) created a free smart-phone app called 'can I fly there?' which allows drone operators to check prohibited areas. This is useful for construction projects in urban areas.

According to O'Reilly (2017) private enterprise and government in Australia have already successfully trialled and established drone activities within their operations. Drone technology has been utilised in areas such as: disaster management and road surveying. Additionally, drones are used in the construction industry in Australia to monitor workers and ascertain safety and adherence to regulation, and also to show progress to clients by feeding them up-to-date visual information. A further use of drones in Australian construction is communication between multiple sites, which increases supervision because contractors cannot be on site permanently but can leave someone in charge and communicate visually and in real-time about site problems (Locker, 2017).

It is submitted that Australian drone regulation is country-specific, and it was the first country worldwide to regulate unmanned aircraft (Library of Congress, n.d). It makes a jurisdictional distinction between recreational flights by personal and commercial 
operators (under 25 kilograms) and it allocates specific areas for this purpose. The prescriptions also regulate drones for commercial use, and CASA's app is very useful to avoid geographic infringements.

\section{$\underline{\text { United Kingdom }}$}

There is already a significant drone economy in the UK today. The CAA figures for August 2018 show there are 4,530 drone operators with permission for commercial operation of drones in the UK. This number represents a significant increase over the last few years. In 2010 there were five commercial permissions for operation, 110 in 2013 and 1,769 in mid-2016.

Although the UK is no longer a member of the European Union (EU), the country is still aligned with EU legislation regarding drones. The UK regulations governing drone usage and the continuing adoption of EU regulations will undoubtedly form part of the current trade negotiations. The European Aviation Safety Agency (EASA) issued Regulation (EU) 2018/1139, which has been enforced in the UK. The Civil Aviation Authority (CAA) has a specialised team dealing with drone regulations. It has issued the Air Navigation Order 2016 (ANO) and the Air Navigation (Amendment) Order 2019. Although the Standardised European Rules of the Air (SERA) has replaced a great deal of legislation in the UK, the above mentioned remain in force (Mosly, 2017).

The basic parameters are contained in the Drone Code issued by CAA (UK Civil Aviation Authority, nd).). The code was introduced into law through the Drone (Regulations) Act 2019, as part of an update to the Air Navigation Order 2016. They include restrictions on height of flights to a maximum of 400 feet, a distance of 150 feet (50 metres) from people and properties, and a distance of 500 feet (150 metres) from crowds and built up areas (UK Civil Aviation Authority, nd).). The drone must be within the operator's line of sight at all times, and from 30th November 2019 the operator must pass a drone test and register with the CAA before flying a drone over 250 grams. It specifies that the responsibility for the drone rests with the remote pilot and breaches can result in criminal prosecution (UK Civil Aviation Authority, n.d). Additionally, endangering the safety of an aircraft is a criminal offence punishable with five years' imprisonment (UK Civil Aviation Authority, n.d).)

Despite regulations there have been incidents of drone misuse reported in the press, and as a consequence, the Department for Transport held a consultation in 2018 and the 
government issued a report, 'Taking flight: The future of drones in the UK' (Department for Transport, 2019). The reports of drone sightings at Gatwick Airport in December 2018 caused significant disruption and highlighted the need for further recognition of the substantial rise in the purchase and use of commercial and civilian drones more widely. The UK government announced swiftly introduced new powers for police to tackle illegal use of drone technology, including powers to land, seize and search drones following the Gatwick Airport fiasco. In addition to the existing restriction to fly a drone within 400 feet $(120 \mathrm{~m})$ or within 1 kilometre from an airport, a new restriction zone will include rectangular extensions measuring 5 kilometres long by 1 kilometre wide from the end of the runway. Additionally, commercial drones will be required to ask permission from Air Traffic Control for instance for carrying inspections (Department for Transport, 2019). The police will be given more powers of enforcement in respect of drones, requiring evidence to be produced regarding drone operator registration and remote pilot acknowledgement of competency. Furthermore, in commercial flights, the police will be empowered to request further information such as the names and addresses of registered drone operators believed to be in charge at the time of infraction, powers of entry and seizure where the police reasonably believes that a drone has been involved in the committing of an offence, and to access the information contained in the drone (Department for Transport, 2019).

Drones are used in construction in the UK, in particular to report project progress, mapping of software programmes, surveying and monitoring. Additionally, drones allow access to areas that are difficult to reach which prevents health and safety issues (PBC, 2017). It is submitted that after Brexit, the United Kingdom will be able to implement drone legislation that is more geographically pertinent, and the new regulations and wide powers given to the police indicate that drone regulation in United Kingdom will become more strict. United Kingdom. Research by NESTA (2018) has concluded that the UK policy responses to drones are outdated as compared to leading countries. The EU in particular have made greater progress towards reforming regulations, creating testbeds and supporting businesses with innovative ideas. Alongside technological development, regulation needs to evolve to allow for the full economic and social benefits to be realised within the UK. 


\section{Accidents and liabilities}

There have been numerous drone incidents worldwide, of various degrees of dangers and liabilities (Conner Forrest, 2018). Most of the incidents have not been fatal, but they have caused a lot of problems where they have been linked to airport runways.

Not only can drone owners and operators be fined by the regulatory authority for not complying with the relevant legislation and regulations, drone owners and operators need to be aware of further criminal charges or civil liability litigation that can result from a drone accident. According to Walker and Stewart (2019) civil liability and criminal court cases in relation to drones are scarce and construction drone cases even rarer, this is primarily because following an accident: (i) legal action is not commenced in the first instance, or; (ii) there is a confidential compensation settlement between the parties thereby obviating legal recourse, and (iii) a legal case has commenced within the court system but the case settles confidentially prior to conclusion of the court case. In United Kingdom in 2019, a British Airways jet carrying 300 passengers from Heathrow Airport to Abu Dhabi came within 20 feet of crashing with an illegally flown drone while at 6,000 feet shortly after take-off. The drone was flying at 15 times the permitted height of 400 feet. A similar incident took place a month previously, involving the Airbus A319 with 160 passengers on board which encountered a drone when trying to land in Manchester airport.

There have also been serious injuries to bystanders: In 2016 in the UK, an 18-monthold toddler had an eyeball sliced in half by the propeller of an out-of-control drone in Worcester,(Mail Online, 2019) and in the US, a drone used in promotion cut off the tip of a photographer's nose (Conner Forrest, 2018).

In respect of liability, there are several issues regarding the use of drones. First, linked to privacy and data protection because even a recreational drone which is equipped with a camera or a recording device can be used for recording images and videos of people who will then be recognised; additionally, it can record data of those people or their business' activities (Opfer and Shields, 2014). Drones can be acquired by any person at a reasonable cost and without prior registration, which makes them high risk as tools for illegal activities; this is compounded by being operated remotely so the pilot can keep out of sight (Opfer and Shields, 2014). 
Drones can fly undetected and it is impossible to determine, at a distance, the data processing equipment it is carrying or for what purpose the data is being collected (Opfer and Shields, 2014).

The current General Data Protection Regulation (GDPR) and the Data Protection Act 2018 are the pertinent legislation in the UK. Any personal data collected by the drone must be processed according to Article 5 GDPR, that is, lawfully, fairly, and transparently; under Article 6 the data subject must give consent to the processing of personal data. Criminal offences can be incurred by drone operators in the United Kingdom where an aircraft is endangered as stated in the Drone Code. Additionally, s. 76 of the Civil Aviation Act 1982 provides for strict liability of the owner or operator of a drone in respect of surface damage, including injury to individuals and property, which requires compensation except in cases of contributory negligence (Phippard et al, 2019). Under the EU Product Liability Directive, (Phippard et al, 2019) manufactures and importers of drones are liable for defective products.

In the US, the FAA Modernisation and Reform Act 2012 (FMRA) does not establish criminal penalties for violations of unmanned aircraft regulations, but a violator may be fined, imprisoned for one year or both. The FMRA requires registration of all drones with the FAA and failure to do so carries civil penalties up to $\$ 27,500$ and criminal penalties of up to $\$ 250,000$, and three-years' imprisonment.

Drone security is also necessary because drones can be easily hacked by sending rogue commands from a laptop to interfere with the drone operation, forcing the aircraft to land or crash. This is done by way of 'exploit', a piece of software directed at a device to take advantage of programming error or flaw on that device. There is no legislation to cover hacks and the data carried by the drone can fall in the wrong hands and be severely compromised. The need to incorporate clear contractual terms is critical therefore because of the absence of case law on drone usage within the construction environment (Walker and Stewart, 2019). There are third party companies providing drone services in construction, in cases where the contractor is not using its own drones.

However, there are no standard terms to accommodate the use of drones in construction projects, thus, liability rests on the individual contract terms which should consider whether the contract falls under the provisions of the Housing Grants, Construction and Regeneration (HGCR) Act 1996 (McCusker, 2018). 
The first section in the relevant part of the 1996 HGCR Act (section 104) seeks to define a "construction contract". Section 104 states that a construction contract is an agreement for:

- the carrying out of construction operations;

- arranging for the carrying out of construction operations by others, whether under sub-contract to him or otherwise; and

- providing his own labour, or the labour of others, for the carrying out of construction operations.

Whether a drone operator contract can be a construction contract depends exclusively on the individual terms. Drone users in construction must make sure they comply with data protection regulations (McCusker, 2018).

While it is important for construction lawyers and project management teams to understand the applicable laws, implement proper operational procedures, and procure appropriate insurance coverage, it is equally important that clients are able to negotiate appropriate contractual provisions. The development of contract language, policies, procedural guidelines, and forms for drone operations should cover the following key provisions:

- A review of applicable law and regulations.

- The creation of site visit release forms, employee materials and job site signage to facilitate notice and consent regarding drone flights and imagery.

- The development procedures for drone accident reporting and response.

- The incorporation of provisions for obtaining and preserving drone imagery, data and other records into litigation hold memos, document collection checklists, and discovery requests; and

- The drafting of contract provisions or a drone rider allocating costs of using drone technology and responsibility for complying with applicable laws

\section{What of the future?}

It is clear from the above analysis that drones are here to stay. This in itself shows that drone technology will continue to be developed, for instance in respect of better batteries to improve flight duration, and new materials used to make drones lighter. 
Companies such as American Robotics have already developed fully automatic drone systems that can fly a route repeatedly without a remote pilot. If such automatic drones become widely used, it is submitted that the current legislation and liabilities may be insufficient.

Commercial drone regulation continues to be an issue that operators across the world cite as their top concern. There are ongoing debates about whether restrictions that vary from region to region and country to country related to drone use are too strict or lax. It is a situation that some have referred to as a "patchwork quilt" of drone regulations, and that has created difficulties for operators and for stakeholders alike interested in the development of a centralized unmanned traffic management (UTM) that would enable automatic drones to operate in a safe and secure manner.

According to the Boston Consulting Group, more organisations will use drones in the future, and it further states that companies are just scratching the surface of what drones can do (Amoukteh et al, 2017). It predicts that over the next two decades, there will be industrial drones used for monitoring facilities and tracking shipments. It is likely that here will be an increase on delivery drones, and it is submitted that this will create a large drone air traffic that will need to be regulated and controlled. NASA is leading a multi-million-dollar programme to develop an automated traffic management system under which drones are capable of safely coordinating manned and unmanned flights. All these advances will be applicable to construction projects. Today, commercial drone flights are manned by a licensed remote pilot who must keep the drone within their line of vision at all times; flights last around one hour or less and the sensors can only collect a few gigabytes of data. However, in future, drones will be able to fly autonomous missions using direction and avoidance technology, which is now being developed and collect large amounts of data. Legislative measures will have to adapt and change.

Construction industry insights suggest that by 2025 , drones will be applied to many project environments. This should provide a rich opportunity for empirical research in this area. While emerging international dialogue towards a legal framework for harmonized regulatory standards may replace the patchwork of soft and hard national drone regulations, market forces such as industry design standards are expected to shape future developments. 
Any innovative technology would typically encounter a number of issues, and it is necessary to identify these issues and try to find the means to avoid them (Mosely, 2017). Further research is needed on issues related to drone usage, including regulatory impact, construction personnel learning curve impact, privacy concerns, and worksite safety issues [Irizarry and Costa, 2016]. Uncertainty regarding the laws and regulations around drone usage represent a barrier to drone integration into construction projects [Mickel, 2016]. Unclear or changing laws and regulations might also drive users away from adopting drone technology

\section{Conclusion}

The application of drones within the construction industry is in its infancy but is foreseen to grow rapidly over the next decade. This paper presents one of the first academic forays into the regulatory and legal aspects of drone operation and usage within the construction environment. Future research might include investigating areas that increase the applications of drone technology in the construction industry; furthermore, it may cover the methods and means of reducing issues in drone usage in the construction industry.

To ensure that construction companies operate drones safely and in accordance with the law, it is important they are aware of and ensure compliance with the legislative and regulatory regime that governs the use of drones. From being completely unregulated, the boom in consumer-grade drone technology has forced governments to enforce new regulations. The international regulation of drones is problematic because it is not drone-specific but largely based on existing regulations for manned civil passenger aircraft. Due to this, countries have imposed specific national regulations to control the use of drones and the potential damage they can cause. As with all new technologies, careful consideration should be given to the concerns that have been raised about the potential risks of drone use and misuse.

Construction companies should be aware of the potential risks of using drones, as well as the potential benefits, so that they can implement strategies to mitigate the risks. In the future, the continuous development of, compliance with and enforcement of the current regulatory regime will become progressively more important. 
Drone technology will be increasingly used in connection with the design and construction of projects, and in the dispute analysis process. For these reasons, construction lawyers and project managers need to stay abreast of how drones are being used and regulated so that they can effectively advise clients on appropriate contract provisions.

\section{BIBLIOGRAPHY}

Australian Government Civil Aviation Safety Authority (not dated), 'Drone safety rules'. Available at: https://www.casa.gov.au/drones/rules/drone-safety-rules Accessed 15 August 2019

Boyle D (2019), 'BA jet carrying 300 passengers from Heathrow to Abu Dhabi came within $20 \mathrm{ft}$ of smashing into an illegally flown drone while flying at $6,000 \mathrm{ft}$ shortly after take-off, report reveals'. Mail Online, available at: https://www.dailymail.co.uk/news/article-7042177/BA-jet-near-miss-drone-6-000feet-Potters-Bar.html Accessed 15 August 2019

Civil Aviation Authority 2018, Reporting misuse of a drone, viewed 2 August 2018, $<$ https://www.caa.co.uk/Consumers/Unmanned-aircraft/General-guidance/Reportingmisuse-of-adrone/>.

Clay D, Trivisonno J (not dated) 'Liability arising from drone operations'. Bar Journal, available at: https://www.walterhav.com/files/2016/10/Sept16_Clay_Trivisonno.pdf Accessed 15 August 2019

Cooke A 2016, 'Video Captures Drone Crashing into Woman's Head, Causing Serious Injury”, 23 June 2016, viewed 6 January 2017, <https://fstoppers.com/aerial/videocaptures-drone-crashingwomans-head-causing-serious-injury-136120>.

Cheung R (2018) 'Dos and don'ts for drone fliers as Hong Kong considers laws to limit and license their use'. South China Morning Post, available at: https://www.scmp.com/lifestyle/article/2140932/dos-and-donts-drone-fliers-hongkong-considers-laws-limit-and-license Accessed 14 August 2019

Claudia Stöcker; Rohan Bennett; Francesco Nex; Markus Gerke and Jaap Zevenbergen (2017) Review of the Current State of UAV Regulations Remote Sens. 9, 459; doi:10.3390/rs9050459

Colomina, I and Molina, P (2014) Unmanned aerial systems for photogrammetry and remote sensing: A review. ISPRS J. Photogramm. Remote Sens. 92, 79-97.

Construction Week Online (2018) ' Japan's Komatsu reveals how to maximise construction drones'. Available at: https://www.constructionweekonline.com/article50289-japans-komatsu-reveals-how-to-maximise-construction-drones Accessed 15 August 2019 
DeCamara, J and McMillan, D (2019) Use of Drones on Construction Projects: Legal and Contractual Considerations. Available at:

https://www.americanbar.org/groups/construction_industry/publications/under_constr uction/2019/winter2019/use-of-drones-on-construction-projects/Accessed on the 2nd April 2020.

Dhande, M (2016) "The current scenario of global drone regulations and laws," Geospatial World, November 19.

Dedrone (not dated) 'Worldwide drone incidents'. Available at: https://www.dedrone.com/resources/incidents/all Accessed 15 August 2019 Drone Law Japan, 'The current law on drones in Japan'. Available at: http://dronelawjapan.com Accessed 15 August 2019

Department for Transport (2019) 'Taking flight: The future of drones in the UK'. Available at:

https://assets.publishing.service.gov.uk/government/uploads/system/uploads/attachme nt_data/file/771673/future-of-drones-in-uk-consultation-response-web.pdf Accessed 15 August 2019

Drone Coach (not dated) 'Drone laws in Hong Kong'. Available at: https://dronecoach.com/drone-laws-in-hong-kong/ Accessed 14 August 2019

Du H, Heldeweg M A (2019) 'An experimental approach to regulating non-military unmanned aircraft systems' (2019) 33(3) International Review of Law, Computers \& Technology, 285-308.

FAA News (2016) Available at: https://www.faa.gov/uas/media/Part_107_Summary.pdf Accessed 14 August 2019

Federal Aviation Administration (2016), 'State and local regulation of unmanned aircraft systems (UAS) available at:

https://www.faa.gov/uas/public_safety_gov/public_safety_toolkit/media/UAS_Fact_S heet_Final.pdf Accessed 14 August 2019

Federal Aviation Administration 2016, Summary of Small Unmanned Aircraft Rule (Part 107), viewed 21 June 2018, <https://www.faa.gov/uas/media/Part_107_Summary.pdf>.

Finnegan, P (2019) 2019 World Civil Unmanned Aerial Systems Market Profile \& Forecast, The Teal Group. https://shop.tealgroup.com/products/2019-world-civilunmanned-aerial-systems-market-profile-forecast

Forrest C (2018) '17 drone disasters that show why the FAA hates drones'. Tech Republic, available at: https://www.techrepublic.com/article/12-drone-disasters-thatshow-why-the-faa-hates-drones/ Accessed 15 August 2019

Hastings Deering 2018, CAT investment in Airware to accelerate rollout of drone program at dealerships, viewed 30 July 2018, <http://www.hastingsdeering.com.au/home/news/drones>. 
Hong Kong Civil Aviation Department, 'Operations of Unmanned Aircraft Systems (UAS)' (not dated) Available at:

https://www.cad.gov.hk/english/Unmanned_Aircraft_Systems.html Accessed 14 August 2019

Irizarry, J. and D. Costa (2016) Exploratory Study of Potential Applications of Unmanned Aerial Systems for Construction Management Tasks. Journal of Management in Engineering. 32(3): p. 1-10.

ICAO (2011) Cir 328, Unmanned Aircraft Systems (UAS) Order Number: CIR328 ISBN 978-92-9231-751-5

Kasprzyk P, Konert A (2018) 'Unmanned aircraft: a new era for aviation and a new era for aviation law?' 23(2) Coventry Law Journal, 53-65

Kawahara R, Niunoya M (2019) 'Construction and projects in Japan: overview' (Practical Law) Resource ID: 9-630-4982

Kespry, John Deere and Kespry (2017) Enter Strategic Alliance to Simplify Drone Integration on Construction Job Sites, viewed 3 July 2018, <https://www.kespry.com/meet-the-press/john-deereand-kespry-forge-globalalliance/>.

Komatsu 2018, Innovative Intelligent Integrated, viewed 30 June 2018, <http://www.komatsu.com.au/AboutKomatsu/NewsAndPublications/News/Document s/iMC_Brochur e_final_webready_V2.pdf>.

Korosec, K 2018, 'Tesla Blames Driver in Latest Fatal Model X Crash' Fortune, viewed 30 April 2018, <http://fortune.com/2018/04/11/tesla-blames-driver-in-latest-fatalmodel-X-crash/) (Apr. 30, 2018>.

Lattanzi, D. and G. Miller (2017) Review of Robotic Infrastructure Inspection Systems. Journal of Infrastructure Systems. 23(3): p. 1-16.

Levin, P (2016) Use of Drones in Construction Expected to Increase in 2016, in Design Cost Data 2016, Design Cost Data Construction Magazine California, USA p. 52-53.

Leung C (2018) 'Drone complaints in 2017 double from 2015, with most cases involving restricted areas, Hong Kong authorities say'. South China Morning Post, available at: https://www.scmp.com/news/hong-kong/hong-kong-law-andcrime/article/2146449/drone-complaints-2017-double-2015-most-cases Accessed 14 August 2019

Library of Congress (not dated) 'Regulation of drones: Australia'. Available at: https://www.loc.gov/law/help/regulation-of-drones/australia.php Accessed 15 August 2019. 
Library of Congress (not dated) 'Regulation of drones: Japan'. Available at: https://www.loc.gov/law/help/regulation-of-drones/japan.php Accessed 15 August 2019

Lockett J 2016, 'Wedding guests sue groom after 'photo drone crashes into their faces while they dance in tent at ceremony', The Sun, 9 December 2016, viewed 15 January 2017, <https://www.thesun.co.uk/news/2365471/wedding-guests-sue-groom-afterphoto-drone-crashes-intotheir-faces-while-they-dance-in-tent-at-ceremony/> .

Liberty Mutual Insurance (2016) 'From drones to defects: Planning for construction's top challenges'. Available at: https://riskandinsurance.com/drones-defects-planningconstructions-top-challenges/ Accessed 14 August 2019

Locker (2017) '4 ways drones have improved the construction industry'. Available at: http://locker.com.au/4-ways-drones-have-improved-the-construction-industry/ Accessed 15 August 2019

Lusher A (2016) 'London woman dies in possibly the first drone-related accidental death'. The Independent, available at: https://www.independent.co.uk/news/uk/homenews/drones-fatal-road-accident-first-non-military-drone-death-accident-car-crashsurveillance-safety-a7180576.html Accessed 15 August 2019

McNabbon, M (2017) Industry Leaders Speak Out About State and Local Drone Regulations. March 10. https://dronelife.com/2017/03/10/industry-leaders-speakstate-local-drone-regulations/

McCusker S (2018) 'Drones are here to stay and help' 29(8) Construction Law, 21-23.

Melo, R., et al (2017) Applicability of unmanned aerial system (UAS) for safety inspection on construction sites. Safety Science, 2017. 98(October): p. 174-185

Meyer, D (2018), 'Uber Reportedly Knows Why Its Self-Driving Tech Didn't Prevent the Deadly Arizona Pedestrian Crash', Fortune, viewed 8 May 2018, <http://fortune.com/2018/05/08/uberautopilot-death-reason/>.

Mickel, C (2016) Despite Clear Benefits the Construction Industry is Slow to Integrate Unmanned Aerial Vehicles into Projects, in Under Construction, American Bar Association Forum on Construction Law. p. 1-8.

Mosly, I (2017). Applications and Issues of Unmanned Aerial Systems in the Construction Industry. International Journal of Construction Engineering and Management, 6(6): 235-239 DOI: 10.5923/j.ijcem.20170606.02

NESTA (2018) Flying High: shaping the future of drones in UK cities Full report, 23 July. https://media.nesta.org.uk/documents/Flying-High-full-reportand-appendices.pdf

Neuman, S (2018), 'Uber Reaches Settlement with Family of Arizona Woman Killed by Driverless Car', The Two-Way, viewed 29 March 2018, <https://www.npr.org/sections/thetwoway/2018/03/29/597850303/uber-reachessettlement-with-family-of-arizona-woman-killed-bydriverless-car>. 
National Drones (2018) '4 of the biggest drone trends for 2018' (2018) Available at: https://blog.nationaldrones.com.au/drone-trends-2018 Accessed 15 August 2019

Nex, F.; Remondino, F (2014) UAV for 3D mapping applications: A review. Appl. Geomat. 2014, 6, 1-15.

Nikkei Asian Review (2015) 'Japan regulates drones overcrowded areas'. Available at: http://dronelawjapan.com/2015/09/29/japan-regulates-drones-over-crowded-areas/ Accessed 15 August 2019

Opfer, N. and D. Shields (2014) Unmanned Aerial Vehicle Applications and Issues for Construction, in 121st ASEE Annual Conference \& Exposition: Indiana, USA. p. $1-15$

Geraldine O'Reilly (2017) Drones and the Law in Local Government; 9 October. https://www.civiclegal.com.au/wp-content/uploads/2018/02/Drones-and-the-Law-inLocal-Government.pdf

Pagallo, U (2012) 'Guns, Ships, and Chauffeurs: The Civilian Use of UV Technology and its Impact on Legal Systems', Journal of Law, Information and Science, vol. 22, no. 2 , pp. 224-233.

PWC (2017) PwC DPS combines drones with artificial intelligence. http://www.pwc.pl/en/publikacje/2016/clarity-from-above.html

Sneiderman-Jhu P (2016) 'Here's is how easy it is to hack a drone and crash it' (2016) Futurity, available at: https://www.futurity.org/drones-hackers-security-1179402-2/ Accessed 15 August 2019

Skyspan International (2017), Press Release in Response to FAA 1/17/17, media release, viewed 20 June 2018, <http://www.skypanintl.com/SkyPan-FAA-PressRelease.pdf>.

Tatum, M. and J. Liu (2017) Unmanned Aircraft System Applications in Construction, in Creative Construction Conference 2017. 2017: Primosten, Croatia.

The Australian Drone Market Report (2019) Hamburg, August 3rd (https://www.droneii.com/wp-content/uploads/2019/08/Australian-Drone-MarketReport-2019-Sample.pdf)

Taillier, S (2014), 'Drone operator fined after UAV crashed into Geraldton triathlete', ABC News, 13 November 2014, viewed 10 January 2018, <http://www.abc.net.au/news/2014-11-13/drone-operatorat-geraldton-marathonfined/5887196>.

UK Civil Aviation Authority (not dated) 'Drone Code'. Available at: https://dronesafe.uk/wp-content/uploads/2019/07/Drone-Code_July2019_WEB.pdf Accessed 15 August 2019 
Uplift Drones (2019), 'Department for Transport release official response detailing the future of drones in the UK' (2019) Available at:

https://www.upliftdronetraining.com/department-for-transport-release-officialresponse-detailing-the-future-of-drones-in-the-uk/ Accessed 15 August 2019

Walker, A and Stewart, R (2019) Construction Drone Accidents: A Worldwide Review of the Legal and Regulatory Environment. CIB World Building Congress 2019 Hong Kong SAR, China 17 - 21 June 2019

Watts, A.C.; Ambrosia, V.G.; Hinkley, E.A (2012) Unmanned aircraft systems in remote sensing and scientific research: Classification and considerations of use. Remote Sens. 4, 1671-1692.

Wong J, Zhang J, Lee J (not dated), 'A vision of the future construction industry in Hong Kong'. Construction Industry Council, Hong Kong, available at: http://www.iaarc.org/publications/fulltext/FFACE-ISARC15-3061494.pdf Accessed 14 August 2019

Zhang,C and Kovacs,J.M (2012) The application of small unmanned aerial systems for precision agriculture: A review. Precis. Agric. 2012, 13, 693-712.

$\underline{\text { Table of Legislation and Treaties }}$

Air Navigation Order 2016

Air Navigation (Amendment) Order 2019

Aviation Act (Japan)

Civil Aviation Act 1982

Convention on Civil Aviation (Chicago Convention) 1944

Data Protection Act 2018

EU Product Liability Directive (85/374/EC)

General Data Protection Regulation

Housing Grants, Construction and Regeneration Act 1996

Industrial Health and Safety Act (Japan)

Modernisation and Reform Act 2012 (USA)

Regulation (EU) 2018/1139

Unmanned Aircraft Rule 2016 (USA) 